tal or the Scottish nation, - an evil which has given title and ascendency to men mean enough to be exalted by such means, and has in some cases enabled them to tread over the heads of their professional brethren, by gulling the public with tinsel decorations, which our high-minded profession is too noble to oppose, too dignified to decry.

As long as the graduates of the University of Edinburgh constitute the majority of the fellows of the ('ollege of Physicians, and as long as any of their members are allowed to pander the honours of the college to their needy retainers, and upon German degrees, giving. to these worthless baubles a British name and a British sanction, so long shall I consider myself at liberty in any way to call down upon the Edinburgh college the whole weight of honest indignation; and I am still of opinion that the University of Edinburgh would have consulted its own dignity far more by attacking the lucre-loving, title-pandering College of Physicians, by endeavouring to blot out the last venal medical corporation in these kingdoms, than by attacking a solitary individual, a British subject, a stranger in a foreign land. Let the university remember the Latin proverb-" Aquila non captat muscas." I am, Sir, your obedient servant,

Birmingham, September 9, 1844.

\section{MEDICAL DEGREES IN PRUSSIA.}

\section{To the Editor of THE LANCET.}

SIR,-In No. 13, and some of the succeeding numbers of your valuable journal, are articles " On the Organisation of the Medical Profession in Germany," founded on Dr. Hoefer's report of a scientific journey in Germany.

Dr. Hoefer's journey lasted four months, and during that time he collected much information. To ne a native of Prussia, and a pupil of one of its principal seats of medical science, the report of Dr.H., appears, at least with regard to Prussia, to contain many erroneous statements. With pleasure would I have ventured to make a few remarks on this report through the medium of your widely-circulated paper, had time and a sufficient knowledge of the English language to enable me to enter into a public controversy, permitted me to do so.

I cannot, however, resist uttering a few words with regard to a letter directed to you, Sir, by "Civis," dated Birmingham, Aug. 19th, and printed in the last number of The Lancet, page 912. In this letter "Civis," informs a certain Dr. Hazlewood how he may obtain the Edinburgh title without examination. "He must procure a degree, by purchase, from Heidelberg, Erlangen Giessen, or some other German seat of medical science."

Now, I beg to avail myself of your columns, to let "Civis," know, that if he at any time should be in want of a German medical degree, and if he obtains it, by purchase, from any Prussian university, without passing through an examination, and having been previously registered for a certain time as a regular student of that university, I declare myself ready to pay for him all the expences of the purchase.

By the way, I would suggest, even to Dr. Hoefer, who calls the examination for the degree in Prussia (the "examen rigorosum") a mere formality, that in case he should feel an inclination to add to his French diploma one of the University of Berlin, he would do well to recal a little to his memory, previous to his going into the examination, the studies of former years, when he was himself a student of medicine, and which studies, perhaps, every one is more or less obliged to neglect in practical life, or the result might be any thing but pleasant. I remain, respectfully, Sir, your most obedient humble servant,

\section{J. H. Steinau}

Doctor of Medicine and Surgery of the Royal University, Berlin.

City-road, Finsbury, Sept. 4, 1814.

* Those of our readers who have read the articles which we published lately on medical education in
Germany, must have been already aware that the Prussian M.D. degree can only be obtained by becoming a student of the university. We are sorry Dr. Steinau has not found time to correct the errors into which he states that Dr. Hoefer, the accredited agent of the French government, has fallen. From the ample opportunities Dr. Hoefer had, owing to his official position, to ascertain the true state of things, and the importance which has been attached in France to his report, we should be inclined to think that any errors which he may have committed, and which we have repeated, cannot be of any great importance. None of the statements contained in his report have been contradicted in Paris, where there are many German graduates, at least not to our knowledge,

\section{ARMY MEDICAL REPORTS.}

\section{To the Editor of THE LANCET.}

SIR,-I see, by a letter, signed "An Army Surgeon," in No. 20 of THE LANCET, February $17 \mathrm{th}$, 1844, that the pruning which my communication of last November underwent, at your discretion, has led to a misunderstanding of my motives, and a misapplication of my expressions. "An Army Surgeon" may be perfectly satisfied, that the exactness and value of the statistical reports, known here as "Major Tulloch's," are duly appreciated by the Indian medical service. The word "convenient," made use of in my letter, was rendered inapplicable by the erasure of words, lines, and paragraphs. I never thought of presuming to question the validity of those records, and alluded to them as the "estimable. statistical reports of Major Tulloch." Probably the disinterested "reviewer" of my "Treatise on Dysentery" (supposed to be a retired Indian surgeon) may be able to inform "An Army Surgeon," better than I can do, " why" these reports bear the gallant officer's name?

In reference to your notice of "Another Army Surgeon's" letter, in No. 21 of The LANCET, I consider it would be out of order for me to attempt to argue with you the point as to whether "Indian army medical statistics" are or are not in the unsatisfactory condition you represent them to be, but I conceive that I may be allowed to claim some acquaintance with the economy of the Calcutta General Hospital, having had under my treatment, during eleven years, half the patients admitted into that institution; nor have $I$ the least hesitation in reiterating the apparently astonishing assertion, that, as compared with "idiopathic dysentery (which with congestive remittent fever, and cholera, may be considered the most fatal diseases of Bengal), hepatitis is a rare complaint in the "lower provinces of this division of India" (i.e. Bengal Proper), the soil of which is alluvial and swampy, and in this opinion I believe I am borne out by the late Mr. Twining, and others who have studied the morbid anatomy of the diseases of Bengal. I do not allude to such pathologists as confound " scurvy, affeeting sailors who make eleven months' voyages," with "dysentery ;" sailors do not constitute the entire class of admissions into the General Hospital of the city of Calcutta, and garrison of Fort William (exclusive of her Majesty's regiment stationed in the fort, which has its own hospital, "next door" to the General Hospital, to draw comparison with which, as regards mortality, and the General Hospital, where inmates are a most miscellaneous collection, shows the animus of "Reviewer," as well as the vague nature of his statistics).

Trusting to your kindness to publish this letter, or as much of it as will correct the impressions which my former epistle has made on "An Army Surgeon," I promise not to trouble you again on the subject. Your obedient servant,

Walter Raleigh, Surgeon, Native Hospital.

Calcutta, May 15, 1844. 